\title{
MJFAS MALAYSIAN JOURNAL OF

\section{Separation time analysis of transient magnetohydrodynamic mixed convection flow of nanofluid at lower stagnation point past a sphere}

\author{
Mohamad Alif Ismail a, ${ }^{*}$, Nurul Farahain Mohammad ${ }^{b}$, Sharidan Shafie a \\ a Department of Mathematical Science, Faculty of Science, Universiti Teknologi Malaysia, 81310 Johor Bahru, Johor, Malaysia \\ b Department of Computational and Theoretical Sciences, Kulliyyah of Science, International Islamic University Malaysia, 25200 Kuantan, Malaysia \\ * Corresponding author: sharidan@utm.my
}

\section{Article history}

Received 24 Feb 2017

Accepted 11 July 2017

Graphical abstract

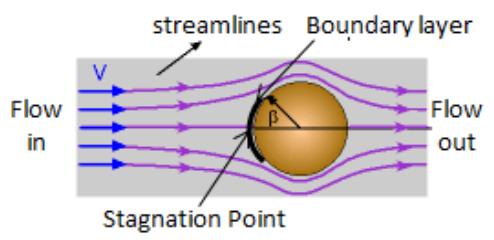

\section{Abstract}

In this paper, the unsteady magnetohydrodynamics (MHD) mixed convection flow of nanofluid at lower stagnation point past a sphere is studied. Nanoparticles $\mathrm{Cu}$ and $\mathrm{TiO}_{2}$ with water as a base fluid are considered. The separation times of the flow as the boundary layer start to separate at the surface of the sphere are given attention. The governing boundary layer equations in the form of partial differential equations are transformed into nonlinear coupled ordinary differential equations and solved numerically using an implicit finite-difference scheme known as Keller-box method. Results of the separation times of boundary layer flow for viscous and nanofluid influenced by magnetic parameter and volume fraction are shown in tabular form and analysed. This study concluded that the separation times can be delayed by added more magnetic particles and small amount the volume fraction.

Keywords: Unsteady flow, mixed convection, nanofluid, magnetohydrodynamic

\section{INTRODUCTION}

Nanofluid can be described as fluid which has nanometer-sized particles suspended in a based fluid. The conventional fluid such as water, oil and ethylene glycol have poor heat transfer characteristic because of the low thermal conductivity of the fluid. Since thermal conductivity play an important role in heat transfer, many research have been done to increase the thermal conductivity for this fluid. One of the method is suspended a nanoparticles in these fluid which is conducted as an agent to enhanced thermal conductivity [1]. Term of nanofluid that refers to the suspended nanoparticles was introduced by Choi [2]. Choi et al. [3] showed that the small amount nanoparticles that is added in a base fluid will increased the thermal conductivity of the fluid itself. Studies of using nanofluid to enhanced heat transfer was started in the book by Das et al. [4], review paper by Maiga et al. [5], Buongiorno [6], Daungthongsuk and Wongwises [7], Trisaksri and Wongwises [8], and Kakac and Pramuanjaroenkij [9].

Mixed convection flow from a solid sphere are important in heat transfer problem because of the tremendous application such as cooling problems in turbine blades, electronic system and manufacturing processes [10]. Yuge [11] and Klaycko [12] started on mixed convection study for viscous incompressible fluid by using experimental work. Then, Hieber and Gebhart [13] solve by using analytical method with certain consideration. After that, Chen and Mucoglu [14, 15] extended using boundary layer approximation with very large Reynolds and Grashof number. Dennis and Walker [16] studied the steady forced convection flow past a sphere at low and moderate Reynolds numbers. El-Shaarawi et al. [17] studied mixed convection about a sphere between moderates and high Reynolds numbers with wide range of viscosity ratio. Nazar et al. [18] investigates the problem for whole sphere by considering constant surface temperature from lower stagnation point up to separation point. Then, Tham et $a l$. [19] extended this problem by taking nanofluids with constant wall temperature as boundary condition. They observed that the volume fraction affected the skin friction as well as heat-transfer coefficient.

Further, Kasim et $a l$. [20] have studied the steady problem on MHD effect on convective boundary layer flow of a viscoelastic fluid embedded in porous medium with Newtonian heating. This studied extend the problem that proposed by Anisah et $a l$. [21] by considering MHD effect. Furthermore, Mohammad et al. [22] studied the effect of MHD on unsteady boundary layer flow past a sphere in viscous fluid. Then, Mohammad et al. [23] extends their problem by considering mixed convection flow and the separation times of the flow has been given a full attention.

Thus, following Mohammad et al. [23], separation times for unsteady mixed convection boundary layer flow past a sphere focuses on nanofluid with MHD effect is studied in this paper. Nanoparticles $\mathrm{Cu}$ and $\mathrm{TiO}_{2}$ diluted into water-based fluid are considered and Tiwari and Das [24] model of nanofluid is referred. In this study, only separation times of boundary layer flow at lower stagnation point is investigated.

The present problem will focus on MHD effect on unsteady mixed convection boundary layer flow but focussing on nanofluid with constant wall temperature. The problem of flow separation also will be considered in this present study.

\section{MATHEMATICAL MODEL}

In this study, we consider unsteady two-dimensional mixed convection boundary layer flow of a nanofluid past a sphere of a radius $a$, which is placed in an incoming stream of nanofluid with a constant 
free-stream velocity of $U_{\infty}$ and constant temperature $T_{\infty}$. It is assume that the force convection is moving upward, while the gravity sector is acts downward. It also assume that the sphere and based fluid (water) is maintained at constant temperature, $T_{w}$ with $T_{w}>T_{\infty}$ for heated sphere (assisting flow) and $T_{w}<T_{\infty}$ for cooled sphere (opposing flow) and ensuring no slip velocity between them. We considered the nanoparticles shape to be spherical and the volume fraction is taken into account.

The basic equations of the problem consist of continuity, momentum, and energy equation in Cartesian coordinates $\bar{x}$ and $\bar{y}$ are [24]

$$
\begin{gathered}
\frac{\partial(\bar{r} \bar{u})}{\partial \bar{x}}+\frac{\partial(\bar{r} \bar{v})}{\partial \bar{y}}=0 \\
\left(\frac{\partial \bar{u}}{\partial \bar{t}}+\bar{u} \frac{\partial \bar{u}}{\partial \bar{x}}+\bar{v} \frac{\partial \bar{u}}{\partial \bar{y}}\right)=-\frac{1}{\rho_{n f}} \frac{\partial \bar{p}}{\partial \bar{x}}+\frac{\mu_{n f}}{\rho_{n f}}\left[\frac{\partial^{2} \bar{u}}{\partial \bar{x}^{2}}+\frac{\partial^{2} \bar{u}}{\partial \bar{y}^{2}}\right] \\
+\frac{\varphi \rho_{s} \beta_{s}+(1-\varphi) \rho_{f} \beta_{f}}{\rho_{n f}} g\left(\bar{T}-T_{\infty}\right) \sin \left(\frac{\bar{x}}{a}\right)-\frac{\sigma B \bar{u}}{\rho_{n f}} \\
\left(\frac{\partial \bar{v}}{\partial \bar{t}}+\bar{u} \frac{\partial \bar{v}}{\partial \bar{x}}+\bar{v} \frac{\partial \bar{v}}{\partial \bar{y}}\right)=-\frac{1}{\rho_{n f}} \frac{\partial \bar{p}}{\partial \bar{y}}+\frac{\mu_{n f}}{\rho_{n f}}\left[\frac{\partial^{2} \bar{v}}{\partial \bar{x}^{2}}+\frac{\partial^{2} \bar{v}}{\partial \bar{y}^{2}}\right] \\
-\frac{\varphi \rho_{s} \beta_{s}+(1-\varphi) \rho_{f} \beta_{f}}{\rho_{n f}} g\left(\bar{T}-T_{\infty}\right) \cos \left(\frac{\bar{x}}{a}\right)-\frac{\sigma B_{0}^{2} \bar{v}}{\rho_{n f}} \\
\frac{\partial \bar{T}}{\partial \bar{t}}+\bar{u} \frac{\partial \bar{T}}{\partial \bar{x}}+\bar{v} \frac{\partial \bar{T}}{\partial \bar{y}}=\alpha_{n f}\left[\frac{\partial^{2} \bar{T}}{\partial \bar{x}^{2}}+\frac{\partial^{2} \bar{T}}{\partial \bar{y}^{2}}\right]
\end{gathered}
$$

subject to boundary conditions

$$
\begin{array}{ll}
\bar{t}<0: & \bar{u}=\bar{v}=0, \quad \bar{T}=T_{\infty} \text { for any } \bar{x}, \bar{y}, \\
\bar{t} \geq 0: & \bar{u}=\bar{v}=0, \quad \bar{T}=T_{w} \text { at } \bar{y}=0 \\
& \bar{u}=\bar{u}_{e}(\bar{x}), \quad \bar{T}=T_{\infty} \text { as } \bar{y} \rightarrow \infty
\end{array}
$$

Where in this study $\bar{u}_{e}=3 / 2 U_{\infty} \sin (\bar{x} / a)$ and $\bar{r}(\bar{x})=a \sin (\bar{x} / a)$. Here $\bar{u}$ and $\bar{v}$ are the velocity components along the $\bar{x}$ and $\bar{y}$ axes, respectively, $\bar{r}(\bar{x})$ is the radial distance from the symmetrical axis to the surface of the sphere, $\bar{u}_{e}(\bar{x})$ is the local free-stream velocity, $T$ is the fluid temperature, $\bar{p}$ is the fluid pressure, $\varphi$ is the nanoparticles volume fraction, $\beta_{f}$ is the thermal expansion coefficient of the fluid fraction, $\beta_{s}$ is the thermal expansion coefficient of solid fraction, $\alpha_{n f}$ is the thermal diffusivity of the nanofluid, $\rho_{n f}$ is the density of the nanofluid, and $\mu_{n f}$ is the viscosity of the nanofluid, which are given by Oztop and Abu Nada [25]

$$
\begin{aligned}
& \alpha_{n f}=\frac{k_{n f}}{\left(\rho c_{p}\right)_{n f}}, \quad \rho_{n f}=(1-\varphi) \rho_{f}+\varphi \rho_{s}, \quad \mu_{n f}=\frac{\mu_{n f}}{(1-\varphi)^{2.5}} \\
& \left(\rho c_{p}\right)_{n f}=(1-\varphi)\left(\rho c_{p}\right)_{f}+\varphi\left(\rho c_{p}\right)_{s}, \\
& \frac{k_{n f}}{k_{f}}=\frac{\left(k_{s}+2 k_{f}\right)-2 \varphi\left(k_{f}-k_{s}\right)}{\left(k_{s}+2 k_{f}\right)+\varphi\left(k_{f}-k_{s}\right)}
\end{aligned}
$$

where $k_{n f}$ is the effective thermal conductivity of the nanofluid, $k_{f}$ is the thermal conductivity of the fluid, $k_{s}$ is the thermal conductivity of solid, $\rho\left(c_{p}\right)_{n f}$ is the heat capacity of the nanofluid, $\rho_{f}$ is the density of fluid fraction, $\rho_{s}$ is the density of the solid fraction and $\mu_{f}$ is the viscosity of the fluid fraction.

To dimensionless the base equations, the following variables are introduced,

$$
\begin{aligned}
& x=\bar{x} / a, \quad y=\operatorname{Re}^{1 / 2}(\bar{y} / a), \quad r(x)=\bar{r}(\bar{x}) / a, \quad u=\bar{u} / U_{\infty}, \\
& v=\operatorname{Re}^{1 / 2}\left(\bar{v} / U_{\infty}\right), \quad T=\left(T-T_{\infty}\right) /\left(\bar{T}-T_{\infty}\right), \quad t=\frac{U_{\infty} \bar{t}}{a} \\
& u_{e}(x)=\bar{u}_{e}(\bar{x}) / U_{\infty}, \quad p=\left(\bar{p}-p_{\infty}\right) /\left(\rho_{n f} U_{\infty}^{2}\right) .
\end{aligned}
$$

where $\operatorname{Re}=U_{\infty} a / v_{f}$ is Reynold number and $v_{f}$ is the kinematic viscosity of the fluid. Substituting these variables into equations (1)-(4) and applied the boundary layer approximation, those equations become

$$
\begin{gathered}
\frac{\partial}{\partial x}(r u)+\frac{\partial}{\partial y}(r v) \\
\frac{\partial u}{\partial t}+u \frac{\partial u}{\partial x}+v \frac{\partial u}{\partial y}=-\frac{\partial p}{\partial x}+\frac{\mu_{n f}}{\rho_{n f} v_{f}} \frac{\partial^{2} u}{\partial y^{2}}+ \\
\lambda \alpha T \sin x-\gamma M u \\
-\frac{\partial p}{\partial y}=0 \\
\frac{\partial T}{\partial t}+u \frac{\partial T}{\partial x}+v \frac{\partial T}{\partial y}=\frac{1}{\operatorname{Pr}} \frac{\alpha_{n f}}{\alpha_{f}} \frac{\partial^{2} T}{\partial y^{2}}
\end{gathered}
$$

where $\operatorname{Pr}$ is the Prandtl number, $\alpha$ is mixed convection parameter, $\mathrm{M}$ is magnetic parameter, $\lambda$ and $\gamma$ which are defined as

$$
\begin{aligned}
& \operatorname{Pr}=\frac{v_{f}\left(\rho C_{p}\right)_{f}}{k_{f}}, \quad \alpha=\frac{G r}{\operatorname{Re}^{2}}, \quad M=\frac{\sigma B_{0}^{2} a}{\rho_{f} U_{\infty}}, \\
& \lambda=\frac{\varphi \rho_{s}\left(\beta_{s} / \beta_{f}\right)+(1-\varphi) \rho_{f}}{\rho_{n f}}, \quad \gamma=\frac{1}{(1-\varphi)+\varphi\left(\rho_{s} / \rho_{f}\right)}
\end{aligned}
$$

with $G r=\frac{g \beta\left(T_{w}-T_{\infty}\right) a^{3}}{v_{f}^{2}}$, being a Grashof number; $\alpha>0$ is for heated sphere and $\alpha<0$ for cooled sphere. Then the boundary condition (5) become

$$
\begin{array}{ll}
t<0: & u=v=0, \quad T=0 \text { for any } x, y \\
t \geq 0: & u=v=0, \quad T=1 \text { at } y=0 \\
& u=u_{e}(x), T=0 \text { as } y \rightarrow \infty
\end{array}
$$

Evaluating equation (9) at outside boundary layer region where

$$
-\frac{\partial p}{\partial x}=u_{e} \frac{\partial u_{e}}{\partial x}+M u_{e}
$$

Substitute (14) into equation (9) and get

$$
\begin{gathered}
\frac{\partial}{\partial x}(r u)+\frac{\partial}{\partial y}(r v) \\
\frac{\partial u}{\partial t}+u \frac{\partial u}{\partial x}+v \frac{\partial u}{\partial y}=u_{e} \frac{\partial u_{e}}{\partial x}+\frac{\mu_{n f}}{\rho_{n f} v_{f}} \frac{\partial^{2} u}{\partial y^{2}}+ \\
\lambda \alpha T \sin x-\gamma M\left(u-u_{e}\right) \\
\frac{\partial T}{\partial t}+u \frac{\partial T}{\partial x}+v \frac{\partial T}{\partial y}=\frac{1}{\operatorname{Pr}} \frac{\alpha_{n f}}{\alpha_{f}} \frac{\partial^{2} T}{\partial y^{2}}
\end{gathered}
$$

Now we use similarity transformation to solve equation (15) to (17), subject to boundary conditions (13). At lower stagnation point of the sphere, where $x=180^{\circ}$ and $\frac{d u_{e}}{d x}=-\frac{3}{2}$. Therefore the similarity variables are defined as 


$$
u=\frac{1}{r} \frac{\partial \psi}{\partial y} \quad \text { and } \quad v=-\frac{1}{r} \frac{\partial \psi}{\partial x}
$$

For small time case, consider

$$
\psi=t^{\frac{1}{2}} u_{e}(x) r(x) f(x, \eta, t), \quad T=s(x, \eta, t), \quad \eta=y / t^{\frac{1}{2}}
$$

Then equation (16)-(17) becomes

$$
\begin{aligned}
& \frac{\mu_{n f}}{\rho_{n f} v_{f}} \frac{\partial^{3} f}{\partial \eta^{3}}+\frac{\eta}{2} \frac{\partial^{2} f}{\partial \eta^{2}}-\frac{3}{2} t\left[1-\left(\frac{\partial f}{\partial \eta}\right)^{2}+f \frac{\partial^{2} f}{\partial \eta^{2}}\right] \\
& +t \gamma M\left(1-\frac{\partial f}{\partial \eta}\right)+\frac{2}{3} t \lambda \alpha s=t \frac{\partial^{2} f}{\partial \eta \partial t} \\
& \frac{\alpha_{n f}}{\alpha_{f}} \frac{\partial^{2} s}{\partial \eta^{2}}+\frac{\operatorname{Pr}}{2} \eta \frac{\partial s}{\partial \eta}-\frac{3}{2} \operatorname{Pr} t f \frac{\partial s}{\partial \eta} \\
& =\operatorname{Pr} t \frac{\partial s}{\partial t}
\end{aligned}
$$

Subject to boundary conditions

$$
\begin{array}{cl}
t<0: & f=0, \frac{\partial f}{\partial \eta}=0, \quad s=0 \text { for any } x, y, \\
t \geq 0: & f=\frac{\partial f}{\partial \eta}=0, \quad s=1 \text { at } y=0 \\
\frac{\partial f}{\partial \eta}=1, \quad s=0 \text { as } y \rightarrow \infty
\end{array}
$$

For large time case, consider

$$
\psi=u_{e}(x) r(x) F(x, Y, t), \quad T=S(x, Y, t), \quad Y=y
$$

Therefore equation (16)-(17) becomes

$$
\begin{aligned}
& \frac{\mu_{n f}}{\rho_{n f} v_{f}} \frac{\partial^{3} F}{\partial Y^{3}}-\frac{3}{2}\left[1-\left(\frac{\partial F}{\partial Y}\right)^{2}+F \frac{\partial^{2} F}{\partial Y^{2}}\right]+\gamma M\left(1-\frac{\partial F}{\partial Y}\right) \\
& +\frac{2}{3} \lambda \alpha S=\frac{\partial^{2} F}{\partial Y \partial t} \\
& \frac{\alpha_{n f}}{\alpha_{f}} \frac{\partial^{2} S}{\partial Y^{2}}-\frac{3}{2} \operatorname{Pr} F \frac{\partial S}{\partial Y}=\operatorname{Pr} \frac{\partial S}{\partial t}
\end{aligned}
$$

Subject to boundary condition

$$
\begin{aligned}
& F=0, \quad \frac{\partial F}{\partial Y}=0, \quad S=1 \quad \text { at } Y=0 \\
& \frac{\partial F}{\partial Y}=1, \quad S=0 \quad \text { as } \quad Y \rightarrow \infty
\end{aligned}
$$

\section{RESULT AND DISCUSSION}

Equations (20)-(21) for small time and (24) to (25) is for large time cases are solved by using numerical scheme named Keller-Box method in MATLAB environment. From this output obtained, the separation times and other physical quantities are presented in tabular form. Two

\begin{tabular}{|c|c|c|c|c|}
\hline$M$ & 0.0 & 0.1 & 1.0 & 1.5 \\
\hline Viscous & 0.4665 & 0.4960 & 1.2760 & - \\
\hline $\mathrm{Cu}$ & 0.4113 & 0.4557 & 0.6407 & 0.8446 \\
\hline $\mathrm{TiO}_{2}$ & 0.4488 & 0.4701 & 1.1063 & 1.8524 \\
\hline
\end{tabular}
different types of nanoparticles, namely $\mathrm{Cu}$ and $\mathrm{TiO}_{2}$ (water as base fluid), have been considered in this study and the range of volume

\begin{tabular}{|c|c|c|c|c|}
\hline$M$ & 0.0 & 0.1 & 1.0 & 1.5 \\
\hline Viscous & 0.3254 & 0.3593 & 0.5842 & 0.9875 \\
\hline $\mathrm{Cu}$ & 0.3556 & 0.3687 & 0.4759 & 0.5700 \\
\hline $\mathrm{TiO}_{2}$ & 0.3587 & 0.3671 & 0.7028 & 1.5630 \\
\hline
\end{tabular}
fraction is $0 \leq \varphi \leq 0.2$. The value of mixed convection parameter is choose as $\alpha=1$ (heated sphere) and $\alpha=-1$ (cooled sphere). Table 1 shows the thermophysical properties water and nanoparticles.
Table 1 The thermophysical properties of fluid and nanoparticles.

\begin{tabular}{|c|c|c|c|c|}
\hline$M$ & 0.0 & 0.1 & 1.0 & 1.5 \\
\hline $\mathrm{Cu}$ & 0.3721 & 0.3744 & 0.4449 & 0.4977 \\
\hline $\mathrm{TiO}_{2}$ & 0.3675 & 0.3735 & 0.4970 & 0.6128 \\
\hline
\end{tabular}

\begin{tabular}{cccc}
\hline Physical Properties & Base Fluid (water) & $\mathrm{Cu}$ & $\mathrm{TiO}_{2}$ \\
\hline $\mathrm{C}_{\mathrm{p}}\left(\mathrm{J} \mathrm{kg}^{-1} \mathrm{~K}^{-1}\right)$ & 4179 & 385 & 686.2 \\
$\rho\left(\mathrm{kg} \mathrm{m}^{-3}\right)$ & 997.1 & 8933 & 4250 \\
$\mathrm{k}\left(\mathrm{W} \mathrm{m} \mathrm{K}^{-1}\right)$ & 0.613 & 400 & 8.9538 \\
$\beta \times 10^{-5}\left(\mathrm{~K}^{-1}\right)$ & 21 & 1.67 & 0.9 \\
\hline
\end{tabular}

In order to verify the solution, the present result are compared with Mohammad et al [23] for $\varphi=0$ at $\operatorname{Pr}=0.7$ and presented in Table 2. The results show an absolute agreement.

Table 2 Comparison of separation time at the surface of a sphere when $\operatorname{Pr}=0.7$ and mixed convection, $\alpha=1$.

\begin{tabular}{cccc}
\hline $\begin{array}{c}\text { Magnetic } \\
\text { parameter } \\
\text { (M) }\end{array}$ & $\begin{array}{c}\text { Prandtl } \\
\text { number (Pr) }\end{array}$ & $\begin{array}{c}\text { Separation times (ts }), \alpha=1 \\
\text { Mohammad } \\
\text { et al. [23] }\end{array}$ & Present \\
\hline 0.1 & 0.7 & 0.6130 & 0.6130 \\
0.5 & 0.7 & 0.9103 & 0.9105 \\
1.0 & 7 & 1.2724 & 1.2724 \\
\hline
\end{tabular}

Table 3 The separation times, $\mathrm{t}_{\mathrm{s}}$ for $\operatorname{Pr}=6.2, \alpha=1$ and $\varphi=0.1$.

Table 4 The separation times, $\mathrm{t}_{\mathrm{s}}$ for $\operatorname{Pr}=6.2, \alpha=-1$ and $\varphi=0.1$

Table 5 the separation times, $\mathrm{t}_{\mathrm{s}}$ for $\operatorname{Pr}=6.2, \alpha=1$ and $\varphi=0.2$.

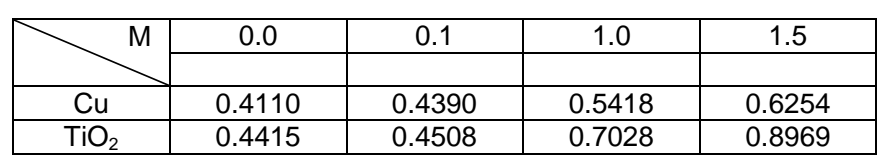

Table 6 The separation times, $\mathrm{t}_{\mathrm{s}}$ for $\operatorname{Pr}=6.2, \alpha=-1$ and $\varphi=0.2$.

Tables 3 and 4 show separation times along the sphere for the various value of magnetic parameter, $\mathrm{M}$ for $\operatorname{Pr}=6.2, \alpha=1$ (assisting flow) and $\alpha=-1$ (opposing flow) for two type of nanoparticles $\mathrm{Cu}$ and $\mathrm{TiO}_{2}$. The separation times of two particles are increase with increasing value of $\mathrm{M}$. The separation times of $\mathrm{TiO}_{2}$ is slightly higher compared to $\mathrm{Cu}$. The same behaviour can be seen for both cases. From these cases it shows that the separation times of $\mathrm{TiO}_{2}$ smaller than $\mathrm{Cu}$ at $M<1$, for $\alpha<1$ (opposing flow) but higher at $M>1$.

Tables 5 and 6 show the separation times when volume fraction $\varphi=0.2$ at $\operatorname{Pr}=6.2$ and $\alpha=1,-1$. For this case, it is also observed that separation times are increased with the increased with magnetic parameter, M. From these tables, it shows that the separation times 
decreased when volume fraction is increased. . This has been proving by Selvakumar and Dhinakaran [27] by doing it experimentally and numerically. However, in this case the $\mathrm{TiO}_{2}$ shown the effectiveness to delay the separation times compared to $\mathrm{Cu}$ for $\alpha=1$. Furthermore, the separation times can be delayed by added more magnetic particles and small amount the volume fraction.

\section{CONCLUSION}

In this paper, we analysed separation times for unsteady magnetohydrodynamic mixed convection boundary layer flow of nanofluid at lower stagnation point past a sphere. We look the effect of volume fraction, $\varphi$ and magnetic, $M$ towards separation times of the flow. There are two types of nanoparticles used in this paper which are $\mathrm{Cu}$ and $\mathrm{TiO}_{2}$. The governing equations are reduce into nondimensionless equations and then transform using appropriate similarity transformation and the solved by using Keller-box method. This study concludes that:

1. The separation times decreased with the increasing of volume fraction $\varphi$.

2. The separation time increased with the increasing of magnetic parameter, $M$.

3. The separation times of $\mathrm{TiO}_{2}$ are higher compare to the $\mathrm{Cu}$ at any magnetic Parameter, $M$ for the both $\alpha$.

4. The separation times of $\mathrm{TiO}_{2}$ is decreased at $\alpha=-1$ when $M<1$.

\section{ACKNOWLEDGEMENT}

This work was financially supported by the Research Management Centre UTM and Ministry of Higher Education Malaysia through votes 13H74, 4F713, and 15H80.

\section{REFERENCES}

[1] Khan, W. A., Pop, I. 2010. Boundary-layer flow of a nanofluid past a stretching sheet. International Journal of Heat and Mass Transfer. 53, 2477-83.

[2] Choi, S. 1995. Enhancing thermal conductivity of fluids with nanoparticles. ASME International Mechanical Engineering Congress and Exposition. 66, 99-105.

[3] Choi, S. U. S., Zhang, Z. G., Yu, W., Lockwood, F. E., Grulke, E. A. 2001. Anomalously thermal conductivity enhancement in nanotube Suspensions. Applied Physics Letters. 79, 2252-2254.

[4] Das, S. K., Choi, S. U. S., Yu, W., Pradet, T. 2007. Nanofluids: Science and Technology. River Street Hoboken, N. J.: Wiley.

[5] Maiga, S. E. B., Palm, S. J., Nguyen, C. T., Roy, G., Galanis, N. 2005. Heat transfer enhancement by using nanofluids in forced convection flows. International Journal of Heat Fluid Flow. 26, 530-46.

[6] Buongiorno, J. 2006. Convective transport in nanofluids. ASME Journal of Heat Transfer. 128, 240-50.

[7] Daungthongsuk, W., Wongwises, S. 2007. A critical review of convective heat transfer nanofluids. Renewable \& Sustainable Energy Reviews. 11 797-817.
[8] Trisaksri, V., Wongwises, S. 2007. Critical review of heat transfer characteristics of nanofluids. Renewable \& Sustainable Energy Reviews. 11, 512-23.

[9] Kakaç, S., Pramuanjaroenkij, A. 2009. Review of convective heat transfer enhancement with nanofluids. International Journal of Heat and Mass Transfer. 52, 3187-3196.

[10] Nazar, R., Amin, N., Pop, I. 2002. Mixed convection boundary layer flow from a sphere with a constant surface heat flux in a micropolar fluid. Journal of Energy Heat and Mass Transfer. 24, 195-212.

[11] Yuge, T. 1960. Experiments on heat transfer from spheres including combined natural and forced convection. Journal of Heat Transfer. 82, 214-220.

[12] Klaychko, L. S. 1963. Heat transfer between a gas and a spherical surface with the combined action of free and forced convection. Journal of Heat Transfer. 85, 355-357.

[13] Hieber, C. A., Gebhart, B. 1969. Mixed convection from a sphere at small Reynolds and Grashof numbers. Journal of Fluid Mechanics. 38, 137-159.

[14] Chen, T. S., Mucoglu, A. 1977. Analysis of mixed forced and free convection about a sphere. International Journal of Heat and Mass Transfer. 20, 867-875.

[15] Mucoglu, A., Chen, T. S. 1978. Mixed convection about a sphere with uniform surface heat flux. Journal of Heat Transfer. 100, 542-544.

[16] Dennis, S. C. R., Walker, J. D. A. 1971. Calculation of the steady flow past a sphere at low and moderate Reynolds numbers. Journal of Fluid Mechanics. 48, 771-789.

[17] El-Shaarawi, M. A. I., Ahmad, N. T., Kodak, Z. 1990. Mixed convection about a rotating sphere in an axial stream. Numerical Heat Transfer. 18, 71-93.

[18] Nazar, R., Amin, N., Pop, I. 2002. On the mixed convection boundarylayer flow about a solid sphere with constant surface temperature. Arabian Journal for Science and Engineering. 27, 117-135.

[19] Tham, L., Nazar, R. Pop, I. 2011. Mixed convection boundary-layer flow about an isothermal solid sphere in a nanofluid. Physica Scripta. 84, 1-13.

[20] Kasim, A. R. M., Mohammad, N. F., Anwar, I., Shafie, S. 2013. MHD effect on convective boundary layer flow of a viscoelastic fluid embedded in porous medium with Newtonian heating. Recent Advances in Mathematics. 182-189.

[21] Dasman, A., Kasim, M., Rahman, A., Mohammad, N. F., Mangi, A., Shafie, S. 2013. Mixed convection boundary layer flow of viscoelastic fluids past a sphere. Defect and Diffusion Forum. 336, 57-63.

[22] Mohammad, N. F., Kasim, A. R. M., Ali, A., Shafie, S. 2013. Effect of MHD on unsteady boundary layer flow past a sphere. Proceedings of the 3rd Annual International Conference Syiah Kuala University (AIC Unsyiah) 2013 in conjunction with the 2nd International Conference on Multidisciplinary Research (ICMR) 2013. 2-4 October. Banda Acheh. 3 , 110-115

[23] Mohammad, N. F., Kasim, A. R. M., Ali, A., Shafie. S. 2014. Separation times analysis of unsteady magnetohydrodynamics mixed convective flow past a sphere. AIP Conference Proceedings - 21st National Symposium on Mathematical Sciences: Germination of Mathematical Sciences Education and Research towards Global Sustainability SKSM 21. 6-8 November 2013. Penang, Malaysia, 1605, 349-354.

[24] Tiwari, R.K., Das, M. K. 2007. Heat transfer augmentation in a two-sided lid-driven differentially heated square cavity utilizing nanofluids. International Journal of Heat and Mass Transfer. 50, 2002-2018.

[25] Oztop, H. F., Abu-Nada, E. 2008. Numerical study of natural convection in partially heated rectangular enclosures filled with nanofluids. International Journal of Heat and Fluid Flow. 29, 1326-1336.

[26] Selvakumar, R. D., Dhinakaran, S. 2016. Unpredictable nature of nanofluid flow: a study on effects of uncertainties in effective viscosity. Procedia Technology. 25, 934-941. 